\title{
Edukasi Pertanian Pada Siswa Dengan Kebun Sekolah Aktif Di SD Muhammadiyah 3 Surakarta
}

\section{Agriculture Education For Student With Active School Garden At SD Muhammadiyah 3 Surakarta}

\author{
Rosyid Dwi Windarto ${ }^{1}$, Rahmatdani Ardian Perkasa ${ }^{2}$, Arifianto Pemdyan Nur $\mathrm{R}^{3}$, Larasati Annisa Bella $\mathrm{K}^{4}$, \\ Rika Mayang Hapsari ${ }^{5}$, Ernoiz Antriyandarti ${ }^{6}$ \\ 1,2,3,6 Program Studi Agribisnis, Fakultas Pertanian, Universitas Sebelas Maret, Surakarta \\ ${ }^{4}$ Program Studi Agroteknologi, Fakultas Pertanian, Universitas Sebelas Maret, Surakarta \\ ${ }^{5}$ Program Studi Agribisnis Hortikultura, Sekolah Vokasi, Universitas Sebelas Maret, Surakarta \\ email:ernoiz_a@staff.uns.ac.id
}

\begin{abstract}
ABSTRAK
Turunnya minat generasi muda terhadap sektor pertanian menjadi salah satu masalah serius yang harus dihadapi dan diantisipasi. Kajian ini bertujuan untuk mengedukasi siswa agar bercocok tanam dengan metode yang lebih mudah sehingga dapat membuka pandangan tentang bercocok tanam dan meningkatkan minat siswa untuk berkebun di SD Muhammadiyah 3 Surakarta. Metode kajian yang digunakan adalah kualitatif dan systematic review. Hasil kajian menunjukkan bahwa edukasi pertanian terhadap siswa dapat dilakukan melalui bertanam dengan metode microgreen. Pemberian materi dilakukan secara daring dengan membagi video tutorial penanaman metode microgreen dan memonitor perkembangan proses edukasi pertanian di SD Muhammadiyah 3 Surakarta. Dengan demikian, setelah pandemi COVID-19 berakhir, dan sekolah mulai dibuka, siswa dapat melanjutkan kegiatan bercocok tanam melalui kebun sekolah aktif. Kendala dalam program ini adalah keterbatasan proses edukasi karena hanya menggunakan metode pembelajaran secara daring (dalam jaringan).
\end{abstract}

Kata Kunci ; Edukasi pertanian; siswa; systematic review; microgreen; pembelajaran daring

\begin{abstract}
The declining interest of the young generation in the agricultural sector is one of the serious problems that must be faced and anticipated. This study aims to educate students to cultivate crops with an easier method in order to open up student views about farming and increase their interest in farming at SD Muhammadiyah 3 Surakarta. This study applies qualitative and systematic review method. The result shows that agricultural education for students could be done through farming using the microgreen method. The online learning can be provided by sharing video tutorials on planting the microgreen method and monitoring the progress of the agricultural education process at SD Muhammadiyah 3 Surakarta. Thus, after the COVID-19 pandemic and schools begin to open, students can continue farming activities through active school gardens. The obstacle in this program is the limitation of the educational process due to it only uses online learning methods.
\end{abstract}

Keywords: Agricultural education; student; systematic review; microgreen; online learning 


\section{PENDAHULUAN}

Menurut LIPI (2019), para pemuda mengalami perubahan persepsi seiring arus modernisasi sehingga menjadi petani tidak lagi menjadi pilihan. Padahal Indonesia membutuhkan petani-petani yang produktif untuk memaksimalkan produksi pangan, terutama karena Indonesia adalah negara agraris. Hal ini disebabkan belum banyaknya sosialisasi atau promosi seputar dunia pertanian yang dilakukan pemerintah ataupun swasta guna mengenalkan pertanian kepada generasi generasi penerus. Selama masa SD terjadi perkembangan kognitif yang pesat pada anak. Anak mulai belajar membentuk konsep, melihat hubungan, dan memecahkan masalah pada situasi yang melibatkan objek konkret dan situasi yang pernah dilihatnya. Anak juga sudah mulai bergeser dari egosentris ke pemikiran yang lebih objektif (Slavin, 2011).

Generasi penerus terkhusus anakanak tingkat Sekolah Dasar (SD) merupakan tonggak paling pertama dalam proses pembukaan mata tentang pertanian. Karenanya sangat penting sejak usia sekolah dasar tersebut disosialisasikan tentang kesadaran mencintai dunia pertanian, sehingga diharapkan nantinya anak-anak sebagai generasi penerus bangsa dapat melestarikan dan memajukan sektor pertanian. Menurut Sutrisno (2005), kegiatan berkebun menjadi salah satu kegiatan yang dapat digunakan untuk mengembangkan fisik motorik anak. Anak dapat mengeksplorasi benda-benda disekitar dan berimajinasi. Selain itu, dengan berkebun dapat belajar sambil bermain dengan teman-teman sehingga tidak merasa bosan dan dan aktif dalam kegiatan. Tangan, kaki dan tubuh anak bergerak sesuai fungsinya masing-masing, sehingga tujuan dari kegiatan tersebut dapat terpenuhi, yaitu adanya pengaruh kegiatan berkebun terhadap perkembangan fisik motorik anak. Kajian ini bertujuan untuk mengetahui bagaimana mengedukasi siswa agar bercocok tanam dengan metode yang lebih mudah sehingga dapat membuka pandangan tentang bercocok tanam dan meningkatkan minat siswa untuk berkebun di SD Muhammadiyah 3 Surakarta.

\section{METODE PENELITIAN}

Kajian ini dilakukan menggunakan metode kualitatif dan systematic review. Observasi ke sekolah dan wawancara langsung kepada informan dilakukan sebelum terjadi pandemi COVID-19. Selama pandemi, wawancara kepada kepala sekolah dan guru dilakukan secara daring. Tinjauan pustaka sistematis merupakan metode untuk memahami kumpulan besar informasi, dan sarana untuk berkontribusi pada jawaban atas pertanyaan penelitian. Systematic review adalah metode pemetaan area ketidakpastian, dan mengidentifikasi di mana hanya sedikit bahkan belum ada penelitian relevan yang telah dilakukan, tetapi diperlukan studi baru (Petticrew dan Roberts, 2006). Kajian ini dilakukan SD Muhammadiyah 3 Surakarta, salah satu sekolah dasar di kota Surakarta yang memiliki potensi kebun sekolah aktif.

\section{HASIL DAN PEMBAHASAN}

\section{A. Gambaran Umum \\ Muhammadiyah 3 Surakarta}

SD

Setiap orang pasti membutuhkan pendidikan, salah satunya dapat diperoleh ketika orang tersebut belajar di sekolah. Sekolah merupakan tempat yang efektif bagi peserta didik untuk belajar sehari-hari. Edukasi atau disebut juga dengan pendidikan merupakan segala upaya yang direncanakan untuk mempengaruhi orang lain baik individu, kelompok, atau masyarakat sehingga mereka melakukan apa yang diharapkan oleh pelaku pendidikan (Notoadmojo, 2003). Edukasi merupakan proses belajar dari tidak tahu menjadi tahu. Pendidikan merupakan kebutuhan yang sangat penting bagi kehidupan manusia dimana pendidikan yang sistematis dan berkualitas perlu terus di upayakan agar tujuan dari proses pendidikan dapat dicapai secara optimal. Pendidikan memiliki arti penting bagi individu dan memberikan pengaruh yang besar terhadap kemajuan suatu bangsa. Disamping itu, kondisi sekolah sangat mempengaruhi jalannya proses belajar mengajar. Dalam hal ini terdapat tiga unsur pendidikan yang sangat mempengaruhi kondisi sekolah yaitu lingkungan sekolah, masyarakat atau warga sekolah, serta sekolah itu sendiri. Apabila ketiga unsur pendidikan tersebut kurang bersinergi, maka sekolah menjadi kurang 
menarik perhatian masyarakat pada umumnya.

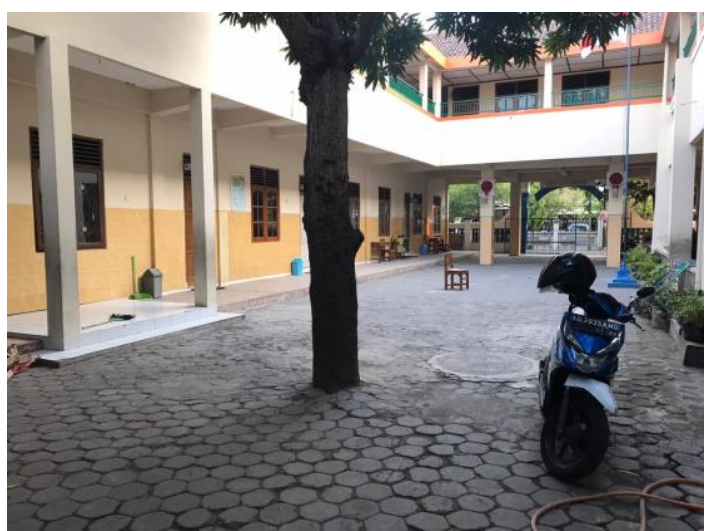

Gambar 1. Halaman SD Muhammadiyah 3 Surakarta

SD Muhammadiyah 3 Surakarta yang beralamatkan di Jl. Singasari Utara I/13 Nusukan, Banjarsari Surakarta, memilki sedikit lahan yang kosong tidak terpakai sehingga dapat ditanami tanaman oleh siswa sendiri dan juga lokasi yang tidak terlalu jauh dari tempat tinggal untuk menghemat biaya. Dari pengamatan visual yang dilakukan dapat disimpulkan bahwa sekolah tersebut hanya memiliki sedikit lahan untuk penghijauan karena luas tanah sekolah mitra ini juga relatif sempit.

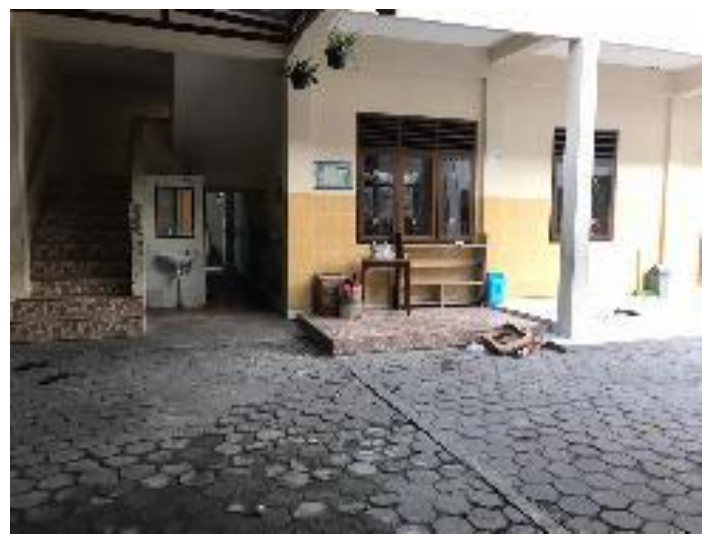

Gambar 2. Lahan Kosong Sekolah

Sekolah tersebut berlokasi ditengah perkampungan yang padat penduduk sehingga diperkirakan tidak bisa memperluas lahannya. Sekolah ini membutuhkan penghijauan yang lebih maksimal agar lebih asri. Di sekolah ini, hampir seluruh lahan kosong yang ada telah tertutup paving. Sebenarnya sudah terdapat lahan penghijauan namun terlihat sangat kurang baik dari segi kuantitas maupun keindahan dan juga kurang terawat. Kesadaran warga sekolah terhadap perawatan kebun sekolah sangat rendah. Kurangnya komoditas jenis tanaman yang ada menjadi salah satu faktor kurang tertariknya minat warga sekolah khususunya siswa siswi SD tersebut untuk ikut serta dalam perawatan kebun sekolah. Selama pandemic Covid-19, kegiatan pembelajaran di SD Muhammadiyah 3 Surakarta dilaksanakan secara daring (dalam jaringan), sehingga kegiatan edukasi pertanian kepada siswa juga dilakukan secara daring. Pihak sekolah khususnya guru yang bertanggung jawab dalam kegiatan pembelajaran melakukan home visiting ke rumah siswa. Guru kelas ini dapat dijadikan mitra dalam kegiatan edukasi pertanian kepada siswa.

\section{B. Edukasi Pertanian kepada Siswa Melalui Kebun Sekolah Aktif}

\section{Pengertian Pertanian}

Pertanian merupakan salah satu kegiatan paling mendasar bagi manusia, karena semua orang perlu makan setiap hari. Pertanian merupakan kegiatan campur tangan manusia (pada tumbuhan asli maupun daur hidup tumbuhan) dalam menanami lahan/tanah dengan tanaman yang akan menghasilkan sesuatu hasil yang dapat dipanen (Sutanto, 2002).

\section{Pengertian Kebun Sekolah Aktif}

Kebun Sekolah sendiri merupakan sebidang lahan atau sebagian luas lahan dari sekolah yang dimanfaatkan untuk menanam tumbuhan yang bermanfaat bagi siswa dan warga sekolah pada umumnya (Ikhsan, 2017).

\section{Pengertian Microgreen}

Microgreen merupakan jenis sayuran yang memiliki kandungan gizi dan vitamin yang lebih tinggi dibandingkan sayuran yang ditanam biasa. Akan tetapi kandungan gizi dan vitamin pada sayuran microgreen akan semakin menurun jika disimpan terlalu lama, namun dapat menjadi substitusi dari sayuran dan cocok ditanama di lahan sempit perkotaan (Arifin, 2016). Microgreen memiliki kandungan gizi lebih tinggi daripada sayuran biasa dan dapat memenuhi kebutuhan gizi manusia sesuai rekomendasi kecukupan asupan nutrisi harian (Bhatt dan 
Sharma, 2018; Xiao et al., 2012; Weber, 2017).

Edukasi pertanian pada siswa dengan mengenalkan microgreen sesuai untuk siswa sekolah dasar karena penanamannya cukup mudah dan efisien untuk dipelajari siswa SD.

\section{Proses Edukasi}

Dalam mengenalkan dan mengedukasi siswa terhadap dunia pertanian, para siswa digerakkan untuk mendapatkan pembelajaran/materi yang menarik dan mudah dipraktekan yaitu microgreen. Terdapat tiga tahapan yang dapat diterapkan, yaitu: 1) pemberian materi tentang pertanian microgreen, 2) meningkatkan keterampilan siswa melalui kegiatan praktek pembuatan microgreen dari tanam hingga panen, 3) mengevaluasi dan mendampingi siswa dalam menerapkan beberapa informasi pengetahuan dan keterampilan yang telah didapatkan Berikut ini adalah proses pembelajaran daring kepada siswa:

\section{Pembuatan Video Tutorial}

Pembuatan video untuk memberikan edukasi cara penanaman microgreen. Video tutorial ini di unggah di kanal youtube lalu dibagikan kepada seluruh Siswa SD Muhammadiyah 3 Surakarta untuk kemudian dipraktekan oleh para siswa di rumah masing-masing.

Tabel 1. Tahapan Kegiatan Edukasi Pertanian Kepada Siswa

\begin{tabular}{|c|c|c|c|}
\hline \multirow[b]{2}{*}{ No } & \multirow[b]{2}{*}{ Rencana Kegiatan } & \multicolumn{2}{|c|}{ Keterlibatan dalam kegiatan } \\
\hline & & Tim Edukasi Pertanian & $\begin{array}{c}\text { Guru SD } \\
\text { Muhammdiyah } 3 \\
\text { Surakarta }\end{array}$ \\
\hline 1 & Koordinasi teknis & $\begin{array}{ll}\text { - } & \text { Menyampaikan ide dan } \\
\text { rencana kegiatan kepada } \\
\text { pihak sekolah }\end{array}$ & $\begin{array}{lr}\text { Memberikan } & \text { informasi } \\
\text { tentang } & \text { proses } \\
\text { pembelajaran di } & \text { SD } \\
\text { Muhammadiyah } & 3 \\
\text { Surakarta } & \end{array}$ \\
\hline 2 & Persiapan Video Tutorial & $\begin{array}{l}\text { Mendesain dan membuat } \\
\text { video tutorial }\end{array}$ & $\begin{array}{l}\text { Memberi masukan alur } \\
\text { cerita video yang menarik } \\
\text { dan mudah dimengerti } \\
\text { siswa }\end{array}$ \\
\hline 3 & $\begin{array}{l}\text { Teori dan praktek melalui } \\
\text { daring tentang penanaman } \\
\text { microgreen }\end{array}$ & $\begin{array}{l}\text { Mengkoordinir, mendampingi } \\
\text { proses transfer teori dan } \\
\text { praktek daring melalui grup } \\
\text { Whatsapp }\end{array}$ & $\begin{array}{l}\text { Membantu mengarahkan } \\
\text { dan membimbing siswa }\end{array}$ \\
\hline 4 & Evaluasi kegiatan & Melakukan evaluasi kegiatan & $\begin{array}{l}\text { Membantu melakukan } \\
\text { evaluasi kegiatan }\end{array}$ \\
\hline
\end{tabular}

Sumber : Data Kajian diolah (2020)

Tabel 2 Indikator Keberhasilan Kegiatan (Utama dan Penunjang)

\begin{tabular}{clllr}
\hline No & \multicolumn{1}{c}{ Indikator } & \multicolumn{1}{c}{ Sebelum kegiatan } & \multicolumn{2}{c}{ Pencapaian Setelah Kegiatan } \\
\hline 1 & Peningkatan & Belum mengerti metode & Mengerti dan & terampil \\
& pengetahuan dan & bercocok tanam & mengaplikasikan & metode \\
& keterampilan & Microgreen & penanaman microgreen & \\
2 & Peningkatan minat & Kurang berminat pada & Peningkatan minat terhadap bidang \\
& & pertanian & pertanian & \\
\hline
\end{tabular}

Sumber : Data Kajian Diolah (2020)

2. Pembuatan Grub Whatsapp

Grub Whatsapp dapat menjadi media untuk pengawasan kegiatan dan menilai keaktifan siswa dalam kegiatan ini sebagai indikator keberhasilan kegiatan edukasi. https://doi.org/10.32528/agribest.v4i2.3617
Pengedukasian juga dilakukan melalui daring dalam grub ini seperti memberikan pengetahuan dan diskusi. Rangkaian kegiatan edukasi pertanian kepada siswa dirangkum oleh Tabel 1. Setelah kegiatan praktek 
microgreen selesai, siswa diberikan diminta mengisi angket evaluasi untuk mengukur keberhasilan proses edukasi. Indikator keberhasilan kegiatan edukasi disajikan pada Tabel 2.

\section{Strategi Keberlanjutan Program}

Untuk menindaklanjuti kegiatan edukasi pertanian dapat dilakukan strategi berikut:

1. Peningkatan informasi melalui daring Menurut Subekti (2017) keberadaan media online dalam proses pembelajaran sangat penting untuk membantu menyampaikan materi pelajaran kepada peserta didik. Menurut Aji (2020) sekolah secara keseluruhan adalah media interaksi antar siswa dan guru untuk meningkatkan kemampuan integensi, ketrampilan dan empati. Tetapi sekarang kegiatan belajar-mengajar di sekolah sementara ditutup karena pandemic Covid-19. Dalam era pandemi Covid-19 ini seluruh kegiatan pemberdayaan memerlukan informasi melalui daring/online sebagai solusi menghindari tatap muka secara langsung. Memberikan informasi melalui daring yaitu seperti pembagian materi terus menerus selain untuk meingkatkan minat baca siswa, juga akan meningkatkan ketertarikan siswa dalam bidang pertanian. Informasi yang mudah diterima dengan gaya bahasa menarik akan lebih mudah mendapatkan atensi dari siswa yang masih berusia dini. Membuka pandangan siswa

tentang internet yang kaya akan informasi dan mudah diakses sehingga akan lebih menarik untuk para siswa mencari informasi baru khususnya dalam bidang pertanian.

2. Pembentukan kelompok tanam

Sekolah membentuk kelompok tanam bagi siswa yang tertarik terhadap dunia pertanian. Untuk kemudian dapat diajarkan sistem pertanian sederhana dan jenis-jenis tanaman lainnya yang lebih beraneka ragam.

\section{KESIMPULAN}

Kegiatan edukasi pertanian kepada siswa sekolah dasar dapat dilakukan melalui kebun https://doi.org/10.32528/agribest.v4i2.3617 sekolah aktif dengan metode microgreen yang mudah diterapkan. Edukasi dilakukan melalui pembelajaran daring dengan membagikan video tutorial dan informasi tentang microgreen serta pendampingan aktif melalui grup Whatsapp. Dari sisi edukasi dan peningkatan keterampilan bertani, metode ini sangat sesuai siswa sekolah dasar. Indikator keberhasilan berdasarkan keaktifan siswa dalam kegiatan ini dan hasil angket yang diberikan kepada masing masing siswa.

Luaran dari kegiatan edukasi pertanian ini adalah siswa mengerti tentang dunia pertanian dan timbul minat untuk mencoba bercocok tanam atau kegiatan pertanian yang lain sejak dini.

Saran yang diberikan peneliti ialah peningkatan informasi melalui daring karena adanya pandemi Covid-19 ini. Peningkatan informasi ini bertujuan untuk membuka wawasan siswa serta membuat siswa untuk lebih tertarik dengan hal-hal yang berkaitan dengan pertanian. Meningkatnya minat siswa terhadap dunia pertanian dapat meningkatkan optimisme regenerasi sector pertanian pada masa yang akan datang.

\section{DAFTAR PUSTAKA}

Aji, Rizqon H S. (2020). Dampak Covid-19 pada Pendidikan di Indonesia: Sekolah, Keterampilan, dan Proses Pembelajaran. Jurnal Sosial \& Budaya Syar-I FSH UIN Syarif Hidayatullah Jakarta Volume 7 (5)

Arifin, R. (2016). Bisnis Hidroponik Ala Roni Kebun Sayur. Jakarta; PT Agromedia

Bhatt, P., \& Sharma, S. (2018). Microgreens: A Nutrient Rich Crop that can Diversify Food System. Int Journal App Bioscience, 6 (2), 182-186.

Ikhsan, Andi. (2017). Pemanfaatan Lingkungan Sekolah sebagai Sumber Belajar di SD Negeri 2 Teunom Aceh Jaya. Jurnal Ilmiah Pendidikan Guru Sekolah Dasar FKIP Unsyiah Volume 2 (1) : 1-11

LIPI. (2015). Minat Bertani Generasi Muda Menurun, Indonesia Terancam Krisis Petani. http://lipi.go.id/berita/minatbertani-generasi-mudamenurunindonesia-terancam-krisispetani/10836. Diakses tanggal 11 Desember 2019 
Notoatmodjo, S. (2003). Pendidikan dan Perilaku Kesehatan. Rineka Cipta: Jakarta

Petticrew, M and Roberts, H. 2006. Systematic Reviews in the Social Sciences. Blackwell Publishing: Oxford.

Slavin, R. (2009). Psikologi Pendidikan: Teori dan Praktik Edisi Kesembilan Jilid I (Sarwiji, B, Ed). Samosir, M. 2011. Jakarta: Penerbit Indeks

Subekti, Ila M. (2017). Analisis Penerapan Media Pembelajaran Berbasis Internet Melalui Pemanfaatan Smartphone Dalam Pembelajaran Pendidikan Pancasila dan Kewarganegaraan (Ppkn) Di Sma Negeri 1 Kartasura. Jurnal Educitizen Volume 2 No. (2)
Sutanto, R. (2002). Pertanian Organik: Menuju Pertanian Alternatif dan Berkelanjutan. Yogyakarta: Kanisius.

Sutrisno \& Harjono, H.S. (2005). Pengenalan Lingkungan Alam Sekitar sebagai Sumber Belajar Siswa. Jakarta: Direktorat Pembinaan Pendidikan Tenaga Kependidikan Dan Ketenagaan Perguruan Tinggi

Weber, C. F. (2017). Broccoli Microgreens: A Mineral-Rich Crop That Can Diversify Food Systems. Frontier in Nutrition. doi: https://doi.org/10.3389/fnut.2017.000 07 